\title{
Prediction of Horizontal Pneumatic Conveying of Large Coal Particles Using Discrete Phase Model
}

\author{
Daolong Yang $\mathbb{D}^{1,2}$ Ge Li, ${ }^{3}$ Yanxiang Wang $\mathbb{D}^{1,2}$ Qingkai Wang, ${ }^{2}$ Jianping $\mathrm{Li}^{3}{ }^{3}$ \\ Qianqian Huang, ${ }^{1}$ Youtao Xia, ${ }^{1}$ and Qian $\mathrm{Li}^{1}$ \\ ${ }^{1}$ School of Mechatronic Engineering, Jiangsu Normal University, Xuzhou 221116, China \\ ${ }^{2}$ State Key Laboratory of Process Automation in Mining \& Metallurgy, Beijing 100160, China \\ ${ }^{3}$ School of Mechatronic Engineering, China University of Mining and Technology, Xuzhou 221116, China \\ Correspondence should be addressed to Daolong Yang; ydl_726@163.com and Yanxiang Wang; wyx_1102@163.com
}

Received 7 November 2019; Revised 12 March 2020; Accepted 6 April 2020; Published 12 May 2020

Academic Editor: Alicia E. Ares

Copyright (C) 2020 Daolong Yang et al. This is an open access article distributed under the Creative Commons Attribution License, which permits unrestricted use, distribution, and reproduction in any medium, provided the original work is properly cited.

The pneumatic conveying focusing on gas-solid two-phase flow plays an important role in a conveying system. Previous work has been conducted in the fields of small particles, where the size was less than $5 \mathrm{~mm}$; however, there are few studies regarding large sizes $(>5 \mathrm{~mm})$. In order to predict the horizontal pneumatic conveying of large coal particles, the coupling methods based on the Euler-Lagrange approach and discrete phase model (DPM) have been used for the simulated research. Compared with the experimental results under the same working condition, the particle trajectory obtained by simulation is similar to the particle distribution at the same position in the experiment, and it turns out that the simulation method is feasible for the horizontal pneumatic conveying of large particles. Multifactor simulations are also carried out to analyse the effects of particle size, flow field velocity, solid-gas rate, and pipe diameter on the wall abrasion during horizontal pneumatic conveying, which provides simulation reference and design guide for pneumatic conveying of large particles.

\section{Introduction}

For a long time, research on fluid flow containing particles has become important in engineering [1-4]. The pneumatic conveying focusing on gas-solid two-phase flow plays an important role in a conveying system. Pneumatic conveying is widely used in energy [5,6], the chemical industry [7], metallurgy $[8,9]$, food processing [10], and other fields. A two-phase flow system is more complex than a single-phase flow system due to the interface effects, relative velocity between the gas and solid, and the randomness of the phase interface. In recent years, scholars have conducted many studies on pneumatic conveying.

Advances in computational fluid mechanics have provided a basis for further insight into the dynamics of pneumatic conveying. Currently, there are two main approaches for pneumatic conveying [11-13]: the Euler-Euler approach and the Euler-Lagrange approach. In the EulerEuler approach, the different phases are treated mathematically as interpenetrating continua $[14,15]$. In the Euler-Lagrange approach, the fluid phase is treated as a continuum by solving the Navier-Stokes equations, while the solid phase is solved by tracking a large number of particles through the calculated flow field $[16,17]$. The solid phase can exchange momentum, mass, and energy with the fluid phase. The particle trajectories are computed individually at specified intervals during the fluid phase calculation. For applications such as these, particle-particle interactions can be included using the discrete phase model (DPM). The DPM is suitable for simulating granular matter $[18,19]$. Such simulations are characterized by a high volume fraction of particles, where particle-particle interaction is important. Previous work has been conducted in the fields of fine particle [20,21], powder [22-24], and seed [25, 26], in which the size was less than $5 \mathrm{~mm}$ and in the range of Geldart A to Geldart C.

This paper mainly studies the pneumatic conveying behavior of large-size coal particles. At present, some 
scholars have carried out simulation and experimental research [27]. Zhou [28-30] used CFD-DEM numerical simulation to study the influence of particle shape and flow field flow pattern on the fragmentation of massive coal particles in pneumatic conveying. At the same time, in order to reduce the air flow speed in pneumatic conveying of coal particles, the influence of swirl strength on the capture speed of bulk coal particles was studied through experiments, and the particle breaking process and energy change law in the large coal particle pneumatic conveying with different pipeline structure and swirl strength were studied. Yang $[8,9]$ first applied the pneumatic conveying to the working face of the coal auger in the extremely thin coal seam and proposed the coal and gangue pneumatic conveying and filling system including the underground separation, the underground transportation, and the pneumatic filling; at the same time, the author designed the precise pressurization system, the high-efficiency dust removal system, and the antiblocking system for the pneumatic conveying of coal particles, which could improve the safety and reliability of pneumatic conveying system for coal with large particle. Yang [31, 32] carried out simulation and experimental research on the pneumatic suspension behavior of large irregular coal particles, obtained the suspension speed of coal particles under different particle sizes, and studied the influence of structural parameters of $5-30 \mathrm{~mm}$ coal particle gas-solid injection feeder on the pure flow field injection performance and particle injection performance through multifactor orthogonal experiment. Li [33] used CFD-DEM coupling method to carry out numerical simulation of swirling pneumatic conveying of large particle size coal, which shows that swirling pneumatic conveying can improve the integrity of particle pneumatic conveying and extend the service life of pipeline. The differences between the above studies and this paper are shown in Table 1.

As shown in Table 1, most simulation studies can only be based on a small number of particles because simulation using CFD-DEM method takes a lot of time. In order to predict the horizontal pneumatic conveying for large coal particles and reduce the simulation time, this paper uses the coupling method based on the Euler-Lagrange approach, DPM, and the particle trajectory equations. The experiment and the simulation of horizontal pneumatic conveying for large coal particles are carried out to verify the feasibility of the simulation method. Multifactor simulations are carried out to analyse the effects of the particle size, flow field velocity, solid-gas rate, and pipe diameter on the pressure drop and wall abrasion, which provides simulation reference and design guide for pneumatic conveying of large particles.

\section{Theory}

The flow field provides the energy required by the particles' motion, and the exchange of momentum and energy between the flow field and particles occurs in the pneumatic conveying flow field. The gas phase is a continuous medium, and considering the influence of the solid phase on the flow field, the continuity equation adds the volume fraction term $\xi$ to exclude the gas volume occupied by the solid phase. The solid phase is a discrete phase, and the motion law of solid particles obeys Newton's second law.

2.1. Gas Phase Equations. It is assumed that the temperature of both the gas and solid phases in pneumatic conveying is the same as that of the atmosphere, and no exothermic reaction occurs between the two phases. Therefore, the energy equation of the gas and solid phases can be ignored.

2.1.1. Gas Phase Continuity Equation. According to the law of mass conservation, the gas phase continuity equation can be obtained and is shown in

$$
\begin{aligned}
\frac{\partial \xi \rho}{\partial t}+\nabla \cdot \rho \varepsilon v & =0 \\
\nabla & \equiv \frac{\partial}{\partial x} \vec{i}+\frac{\partial}{\partial y} \vec{j}+\frac{\partial}{\partial z} \vec{k} .
\end{aligned}
$$

2.1.2. Gas Phase Momentum Equation. The momentum equation of the gas phase can be obtained from the law of momentum conservation, which is similar to the continuity equation.

$$
\frac{\partial \xi \rho v}{\partial t}+\nabla \cdot \rho \xi \mu v=-\nabla \rho+\nabla \cdot(\xi \mu \nabla v)+\rho \xi g-S_{m} .
$$

The momentum transfer $S_{m}$ refers to the sum of the fluid drag in the fluid unit.

$$
S_{m}=\frac{\sum F_{d}}{V} .
$$

2.1.3. Turbulence Transmission Equations. The realizable $k-\varepsilon$ model [34] has the advantage of more accurate prediction for the divergence ratio of flat and cylindrical jets, and its transmission equations are

$$
\begin{aligned}
\frac{\partial}{\partial t}(\rho k)+\frac{\partial}{\partial x_{j}}\left(\rho k v_{j}\right)= & \frac{\partial}{\partial x_{j}}\left[\left(\mu+\frac{\mu_{t}}{\sigma_{k}}\right) \frac{\partial k}{\partial x_{j}}\right] \\
& +G_{k}+G_{b}-\rho \varepsilon-Y_{M}+S_{k} \\
\frac{\partial}{\partial t}(\rho \varepsilon)+\frac{\partial}{\partial x_{j}}\left(\rho \varepsilon v_{j}\right)= & \frac{\partial}{\partial x_{j}}\left[\left(\mu+\frac{\mu_{t}}{\sigma_{\varepsilon}}\right) \frac{\partial \varepsilon}{\partial x_{j}}\right] \\
& +\rho C_{1} S \varepsilon-\frac{\rho C_{2} \varepsilon^{2}}{k+\sqrt{v \varepsilon}}+\frac{C_{1 \varepsilon} C_{3 \varepsilon} G_{b} \varepsilon}{k}+S_{\varepsilon}
\end{aligned}
$$

with

$$
\left\{\begin{array}{l}
C_{1}=\max \left[0.43, \frac{\eta}{\eta+5}\right], \\
\eta=\sqrt{2 S_{i j} S_{i j}} \frac{k}{\varepsilon}
\end{array}\right.
$$


TABLE 1: The differences between the above studies and this paper.

\begin{tabular}{|c|c|c|c|}
\hline & Particle & Method & Research contents \\
\hline $\begin{array}{l}\text { This } \\
\text { paper }\end{array}$ & $\begin{array}{c}\text { Coal particle } \\
\text { Size (experiment): } 5-25 \mathrm{~mm} \\
\text { Size (simulation): } 5,10,15,20,25 \mathrm{~mm} \\
\text { Number (experiment and simulation): } \\
1.12,2.25 \mathrm{~kg} / \mathrm{s}\end{array}$ & $\begin{array}{c}\text { Experiment } \\
\text { Euler-Lagrange approach and } \\
\text { DPM }\end{array}$ & Predict horizontal pneumatic conveying \\
\hline [28] & $\begin{array}{c}\text { Coal particle } \\
\text { Size: } 25 \mathrm{~mm} \\
\text { Number: only } 1\end{array}$ & CFD-DEM & $\begin{array}{c}\text { Particle shape and swirling intensity in pneumatic } \\
\text { conveying }\end{array}$ \\
\hline [29] & $\begin{array}{l}\text { Coal particle } \\
\text { Size: } 5-15 \mathrm{~mm} \\
\text { Number: } 100 \mathrm{~g} \\
\text { Coal particle }\end{array}$ & Experiment & $\begin{array}{l}\text { Swirling intensity and pickup velocity in } \\
\text { pneumatic conveying }\end{array}$ \\
\hline$[30]$ & $\begin{array}{c}\text { Size: } 25 \mathrm{~mm} \\
\text { Number: only } 1 \\
\text { Coal particle }\end{array}$ & CFD-DEM & Particle breakage in pneumatic conveying \\
\hline$[31]$ & $\begin{array}{c}\text { Size (experiment): } 5-30 \mathrm{~mm} \\
\text { Size (simulation): } 5,10,15,20,25,30 \mathrm{~mm} \\
\text { Number (experiment and simulation): } \\
\text { only } 1 \\
\text { Coal particle }\end{array}$ & $\begin{array}{l}\text { Experiment } \\
\text { CFD-DEM }\end{array}$ & $\begin{array}{l}\text { Suspension behavior in vertical pneumatic } \\
\text { conveying }\end{array}$ \\
\hline [32] & $\begin{array}{l}\text { Size: } 5-30 \mathrm{~mm} \\
\text { Number: } 5 \mathrm{~kg} \\
\text { Coal particle }\end{array}$ & Experiment & Injection performance of the gas-solid injector \\
\hline [33] & $\begin{array}{l}\text { Size (experiment): } 5-7,7-9,9-11,11-13 \text {, } \\
\text { 13-15 mm } \\
\text { Size (simulation): } 5,10,15 \mathrm{~mm} \\
\text { Number (experiment): } 1.85 \mathrm{~kg} / \mathrm{s} \\
\text { Number (simulation): } 1.50 \mathrm{~kg} / \mathrm{s} \text { (total } 3 \mathrm{~kg} \text { ) }\end{array}$ & $\begin{array}{l}\text { Experiment } \\
\text { CFD-DEM }\end{array}$ & Swirling flow in pneumatic conveying \\
\hline
\end{tabular}

\subsection{Motion Equations of the Solid Phase}

2.2.1. Particle Motion Equation. The particle motion equation obtained from Newton's second law is

$$
m_{p} \frac{d \mathbf{v}_{p}}{d t}=\mathbf{G}+\mathbf{F}_{d}+\mathbf{F}_{S}
$$

The drag force $\mathbf{F}_{d}$ of a particle in the uniform flow field is as follows:

$$
\mathbf{F}_{d}=\frac{3}{4} \frac{\rho m_{p}}{\rho_{p} d_{p}} c_{D}\left(\mathbf{v}-\mathbf{v}_{p}\right) .
$$

The drag coefficient parameter $c_{D}$ is assumed as a constant, that is, $c_{D}=0.44$, and the Saffman lift force $\mathbf{F}_{S}$ of a particle is as follows:

$$
\mathbf{F}_{S}=\frac{2 K v^{1 / 2} \rho d_{i j}}{\rho_{p} d_{p}\left(d_{l k} d_{k l}\right)^{1 / 4}}\left(\mathbf{v}-\mathbf{v}_{p}\right) .
$$

Equation (10) generated from the velocity gradient is obtained by Li and Ahmadi [35] and was based on the analytical result of Saffman [36].

2.2.2. Particle Trajectory Equations. The force of a single particle in the flow field is shown in Figure 1 [37, 38]. The particle force in the $x$ direction is mainly the fluid drag force; those in the $y$ direction are the particle gravity, fluid drag force, and Saffman lift force; and those in the $z$ direction are the fluid drag force and Saffman lift force. The force equations of a particle acquired are shown in equation (11)equation (13):

For $x$ direction,

$$
m_{p} \frac{d^{2} \mathbf{x}_{p}}{d t^{2}}=\mathbf{F}_{d x}
$$

For $y$ direction,

$$
m_{p} \frac{d^{2} \mathbf{y}_{p}}{d t^{2}}=\mathbf{G}+\mathbf{F}_{d y}+\mathbf{F}_{S y} .
$$

For $z$ direction,

$$
m_{p} \frac{d^{2} \mathbf{z}_{p}}{d t^{2}}=\mathbf{F}_{d z}+\mathbf{F}_{S z}
$$

There is an assumption that the initial positions of the particles are $x_{p 0}, y_{p 0}$, and $z_{p 0}$ at the beginning and that $c_{D}$ is constant when the particle moves on as time goes by. The particle trajectory equations in the three directions are obtained by integration twice.

For $x$ direction,

$$
\mathbf{x}_{p}=x_{p 0}+\mathbf{v}_{x} t-\frac{\ln \left(a \mathbf{v}_{r x} t+1\right)}{a} .
$$

For $y$ direction,

$\mathbf{y}_{p}=y_{p 0}+\left(\mathbf{v}_{y}+\frac{b}{2 a}-\frac{c}{\sqrt{a}}\right) t+\sqrt{\frac{f}{a c^{2}}} \ln \frac{f e^{2 c t}-e^{2 c t}}{f e^{2 c t}-1}$.

For $z$ direction, 


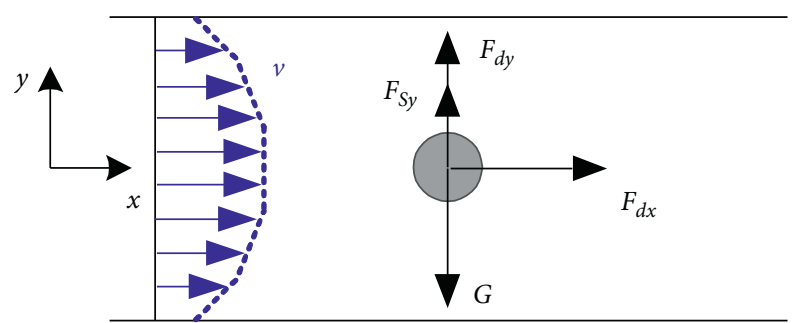

(a)

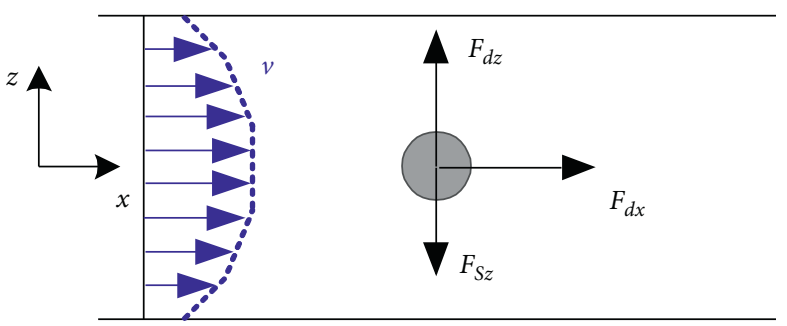

(b)

FIgURE 1: Particle forces in horizontal flow field.

$$
\mathbf{z}_{p}=z_{p 0}+\mathbf{v}_{z} t-\sqrt{\frac{n}{a} \ln \frac{n e^{b t / \sqrt{a}}-1}{n e^{b t / \sqrt{a}}} .}
$$

The parameters $a, b, v_{r i}, f$, and $n$ are given by

$$
\left\{\begin{array}{l}
a=\frac{4 \rho_{p} d_{p}}{3 \rho c_{D}}, \\
b=\frac{2 K v^{1 / 2} \rho d_{i j}}{m_{p} \rho_{p} d_{p}\left(d_{l k} d_{k l}\right)^{1 / 4}} \\
\mathbf{v}_{r i}=\mathbf{v}-\mathbf{v}_{p} \\
f=\frac{2 a v_{r i}-b-\sqrt{b^{2} \pm 4 a g}}{2 a v_{r i}-b+\sqrt{b^{2} \pm 4 a g}} \\
n=\frac{a \mathbf{v}_{r i}-b}{a \mathbf{v}_{r i}} .
\end{array}\right.
$$

The particles will be impacted with the wall and other particles in the pipe, and the collision recovery factor is obtained by Forder's recovery factor equations [39].

$$
\left\{\begin{array}{l}
e_{n}=0.988-0.78 \theta+0.19 \theta^{2}-0.024 \theta^{3}+0.027 \theta^{4} \\
e_{r}=1-0.78 \theta+0.84 \theta^{2}-0.21 \theta^{3}+0.028 \theta^{4}-0.022 \theta^{5}
\end{array}\right.
$$

2.3. Pipe Abrasion. The pipe abrasion in pneumatic conveying belongs to the contact between the particles and the wall. The abrasion rate of the pipe wall is defined as

$$
R_{e r}=\sum_{p=1}^{N_{p}} \frac{m_{p} C\left(d_{p}\right) f(\alpha) v_{r}^{b(v)}}{A_{w}}
$$

The variables $d_{p}, m_{p}$, and $A_{w}$ are obtained from the boundary conditions and pipe meshing. The variables $\alpha$ and $v_{r}$ are obtained in the solving process of the particle trajectory. The piecewise linear function of the impact angle $f(\alpha)$ used in the impact between the coal particles and the pipe wall is the abrasion parameter of sand and carbon steel [40].

$$
f(\alpha)= \begin{cases}0.04 \alpha, & 0 \leq \alpha<20^{\circ}, \\ 0.8+0.02\left(\alpha-20^{\circ}\right), & 20^{\circ} \leq \alpha<30^{\circ}, \\ 1-\frac{\left(\alpha-30^{\circ}\right)}{30}, & 30^{\circ} \leq \alpha<45^{\circ}, \\ 0.5-\frac{\left(\alpha-45^{\circ}\right)}{45}, & 45^{\circ} \leq \alpha \leq 90^{\circ} .\end{cases}
$$

\section{Experiments}

The experiment system of horizontal pneumatic conveying is shown in Figure 2. The total length of the conveying pipelines is $10 \mathrm{~m}$, and the diameter is $70 \mathrm{~mm}$. The test system included two pressure transducers, a signal amplifier, a data acquisition instrument, and a computer. The positions of the two pressure transducers and one transparent pipe are shown in Figure 2.

The air flow is pressurized by the screw air compressor and stabilized by the air receiver, and it then enters into the gas-solid injector through the flow valve. The coal particles gain kinetic energy from the air flow and are conveyed into the dust collection box through the conveying pipes. There is some back pressure in the dust collection box, but it is far less than the pressure of the air flow. Therefore, the dust collector can be considered as under atmospheric pressure. The first pressure transducer is installed $3 \mathrm{~m}$ from the outlet of the gas-solid injector, and the second is $4 \mathrm{~m}$ downstream of the first pressure transducer. The transparent pipe is installed $1.5 \mathrm{~m}$ downstream of the first pressure transducer to monitor the particle motion state.

When the output pressure of the air compressor is certain, the opening of the flow valve determines the air flow rate in the pipe. It is called pure flow field when no particles enter into the flow field. However, when the particles enter into the flow field, some of the flow field dynamic pressure turns to static pressure to transfer momentum and energy to the particles. At this point, it amounts to adding back pressure in the pipe. As a result, the air flow rate will be reduced by this back pressure. Therefore, the air flow rate of the pure flow field is regarded as the reference standard in the experiments. When the particles enter into the flow field, 


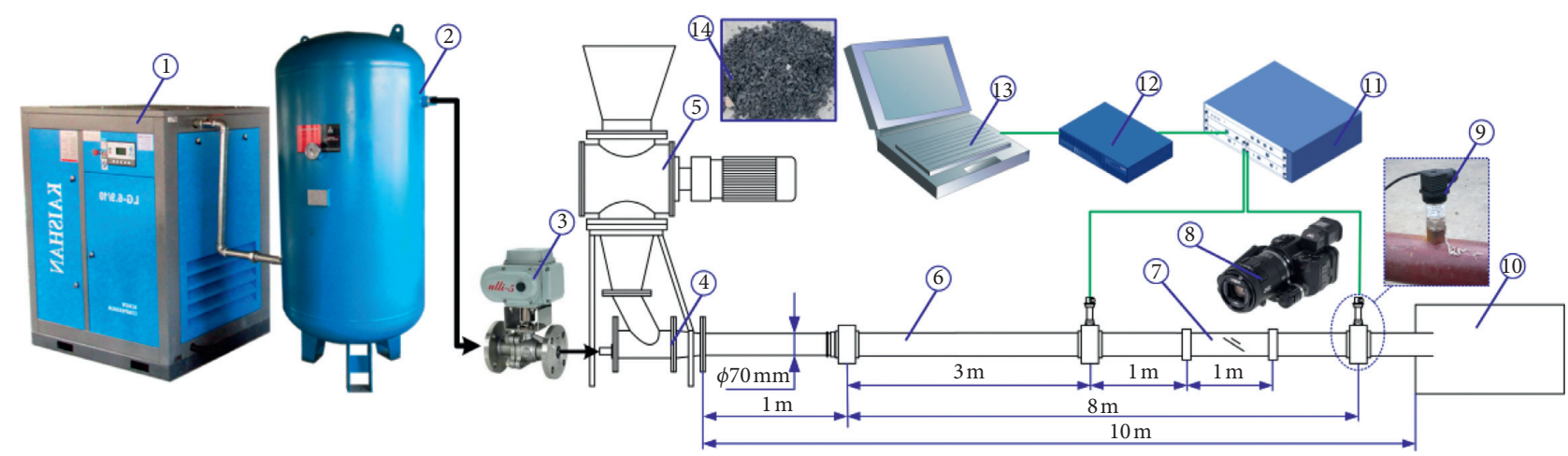

FiguRE 2: Experiment system of horizontal pneumatic conveying. 1, screw air compressor; 2, air receiver; 3, flow valve; 4, gas-solid injector; 5 , feeder; 6, conveying pipes; 7, transparent pipe; 8 , high-speed camera; 9 , pressure transducer; 10, dust collection box; 11, signal amplifier; 12 , data acquisition instrument; 13 , computer; 14 , coal particles.

the opening of the flow valve will be appropriately increased to complement the reduction.

The size of the experiment coal particles is $5-10 \mathrm{~mm}$, and the feeding rate is controlled by the frequency converter. The density of the experiment coal particles is $2100 \mathrm{~kg} / \mathrm{m}^{3}$. The experiment scheme is shown in Table 2.

\section{Simulations}

4.1. Mesh Independence Simulations. The Euler-Lagrange approach and DPM are used in the simulations. The hexahedral meshes to mesh the $3 \mathrm{~m}$ pipe model and the simulation parameters are shown in Figure 3. The mesh parameters of mesh independence simulation are shown in Table 3. The inner diameter of the pipe is $150 \mathrm{~mm}$, the distance between the particle injection surface and the pipe inlet is $400 \mathrm{~mm}$, the distance between the measurement surface and the pipe inlet is $2.5 \mathrm{~m}$, and the simulation time is 2 s. Taking the average velocity of the particles and the average velocity of the flow field of the measurement section as the index, 25 groups of simulation are carried out with 5 particle sizes.

The simulation results of mesh independence show that when the particle size is 2 times of the minimum grid size, the grid size has little effect on the particle velocity, which is also consistent with Aitaliyahia's research results [41]. Therefore, the minimum grid size used in the simulation of different particle sizes in the text is shown in Table 4.

4.2. Horizontal Pneumatic Conveying Simulations. In the horizontal pneumatic conveying simulations, the mesh parameters in Table 4 are used for simulations under different particle sizes and the boundary conditions and injection parameters are shown in Figure 4. The simulation pipe diameters are $70 \mathrm{~mm}, 100 \mathrm{~mm}$, and $150 \mathrm{~mm}$, and the length is $6 \mathrm{~m}$. The wall roughness of seamless steel pipes used in the experiments is $0.05 \mathrm{~mm}$. The particle density is $2100 \mathrm{~kg} / \mathrm{m}^{3}$. The particles are uniformly generated on the particle face and enter the flow field at the speed of $V_{x}=1 \mathrm{~m} /$ s. The transmission medium is air, which is considered as an incompressible gas. The gas density is $1.225 \mathrm{~kg} / \mathrm{m}^{3}$, and the dynamic viscosity is $1.8 \times 10^{-5} \mathrm{~kg} / \mathrm{m}^{3}\left(20^{\circ} \mathrm{C}, 1 \mathrm{~atm}\right)$. The simulation considered the interaction between the gas and particle phases; however, the shape characteristics of the particles are ignored.

\section{Results and Analysis}

5.1. Particle Trajectories in Experiment. A high-speed camera is used to record the particles' movement. The instantaneous images of the experiment videos in the stable conveying part are shown in Figure 5.

When the flow field velocity is small (Figures 5(a) and $5(\mathrm{e})$ ), the images of the stable conveying part under the two feeding rates show an obvious stratification phenomenon. The flow field is divided into three layers: the fluid layer, the conveying layer, and the deposition layer. The fluid layer area is mainly high-velocity fluid. The conveying layer area mixes the particles and the fluid where the flow field promotes the particles' movement. The small particles are mainly in this layer. The deposition layer area is mainly the large particles with a lower velocity. The particle fluidity in this layer is poor, and it is difficult to promote the particles' movement. When the flow field velocity is gradually increased (Figures 5(b) and 5(f)), the images show that the layer boundary appears to be blurred, and the fluid layer and the deposition layer are reduced. The particle movement range increases, and the static and low velocity particles at the pipe bottom decrease. As the flow field velocity continues to increase (Figures 5(c) and 5(g)), the images show that the stratification has basically disappeared. The particle conveying status is relatively dense. The particles at the bottom of the pipe also move with the flow field. While the flow velocity increases further (Figures 5(d) and 5(h)), the images show that the spacings between the particles and the particle velocity are both increasing. There are some small interruptions in the conveying area under a large feed rate (shown in Figure 5(h)), which means that the particle conveying status is changing to the dilute phase state.

5.2. Comparison of the Particle Trajectories between Simulation and Experiment. The simulation and experiment results 
TABLE 2: The experiment scheme of horizontal pneumatic conveying.

\begin{tabular}{|c|c|c|c|c|}
\hline No. & Output pressure of air compressor $(\mathrm{MPa})$ & Flow field velocity & Feeding rate & Solid-gas rate \\
\hline 1 & 0.3 & $21 \mathrm{~m} / \mathrm{s}$ & $1.12 \mathrm{~kg} / \mathrm{s}$ & 11.37 \\
\hline 2 & 0.4 & $29 \mathrm{~m} / \mathrm{s}$ & $1.12 \mathrm{~kg} / \mathrm{s}$ & 8.23 \\
\hline 3 & 0.5 & $37 \mathrm{~m} / \mathrm{s}$ & $1.12 \mathrm{~kg} / \mathrm{s}$ & 6.45 \\
\hline 4 & 0.6 & $44 \mathrm{~m} / \mathrm{s}$ & $1.12 \mathrm{~kg} / \mathrm{s}$ & 5.43 \\
\hline 5 & 0.3 & $21 \mathrm{~m} / \mathrm{s}$ & $2.25 \mathrm{~kg} / \mathrm{s}$ & 22.74 \\
\hline 6 & 0.4 & $29 \mathrm{~m} / \mathrm{s}$ & $2.25 \mathrm{~kg} / \mathrm{s}$ & 16.49 \\
\hline 7 & 0.5 & $37 \mathrm{~m} / \mathrm{s}$ & $2.25 \mathrm{~kg} / \mathrm{s}$ & 12.91 \\
\hline 8 & 0.6 & $44 \mathrm{~m} / \mathrm{s}$ & $2.25 \mathrm{~kg} / \mathrm{s}$ & 10.85 \\
\hline
\end{tabular}

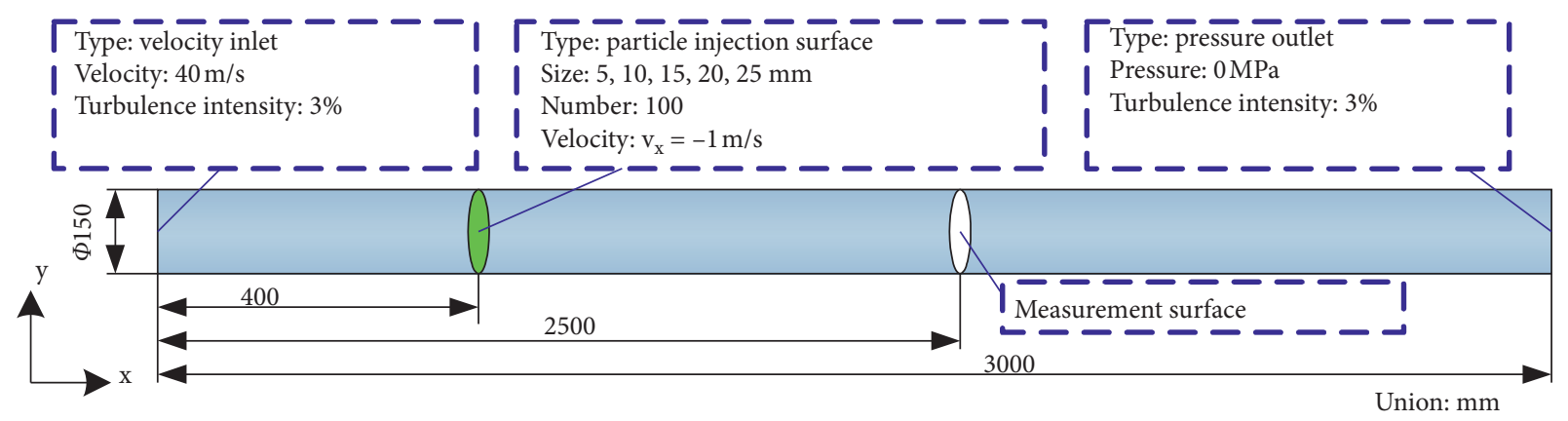

Figure 3: Mesh independence model.

TABle 3: The mesh parameters of mesh independence simulation.

\begin{tabular}{lccc}
\hline $\begin{array}{l}\text { Simulation } \\
\text { no. }\end{array}$ & $\begin{array}{c}\text { Min. mesh size } \\
(\mathrm{mm})\end{array}$ & $\begin{array}{c}\text { Mesh } \\
\text { number }\end{array}$ & $\begin{array}{c}\text { Particle size } \\
(\mathrm{mm})\end{array}$ \\
\hline $1-5$ & 10 & 33276 & $5,10,15,20,25$ \\
$6-10$ & 20 & 7904 & $5,10,15,20,25$ \\
$11-15$ & 30 & 2505 & $5,10,15,20,25$ \\
$16-20$ & 40 & 1216 & $5,10,15,20,25$ \\
$21-25$ & 50 & 720 & $5,10,15,20,25$ \\
\hline
\end{tabular}

of particle motion are shown in Table 5. The experiment results are the particle positions from the instantaneous images in Figure 5. The simulation results are the particle trajectories in the range of 5-5.5 $\mathrm{m}$ from the particle factory in the simulation pipe. Comparing the experiment and simulation results, the particle motion state in the simulation results is basically similar to that in the experiment, which means that the simulation method is feasible for the horizontal pneumatic conveying of large particles. The feeding rate is $1.12 \mathrm{~kg} / \mathrm{s}$ in groups No.1 to No.4, and the feeding rate is $2.25 \mathrm{~kg} / \mathrm{s}$ in groups No.5 to No.8.

It can be found that the particle concentration in the results of simulations and experiments decreases with the flow field velocity under the same feeding rate. In No.1 and No.5, the conveying status is divided into three layers in both the simulation and experiment results due to the small flow field velocity. In the simulation results, the particle trajectories are dense in the pipe bottom, the middle layer has some particle trajectories, and the top layer has little particle trajectories. The stratification phenomenon gradually disappears with the increase in the flow field velocity. It also can be seen from the simulation results that the particle-particle collisions and particle-wall collisions become more severe with the increase in the flow field velocity.
TABLE 4: The mesh parameters for different particle sizes.

\begin{tabular}{lc}
\hline Min. mesh size $(\mathrm{mm})$ & Particle size $(\mathrm{mm})$ \\
\hline 10 & 5 \\
20 & 10 \\
30 & 15 \\
40 & 20 \\
50 & 25 \\
\hline
\end{tabular}

\subsection{Simulation Results}

5.3.1. Particle Trajectories. The part of the particle trajectories in the horizontal pipe is shown in Figure 6. The solidgas rate in the simulation is 10 . The particle size is different in Figures 6(a) and 6(b), the flow field velocity is different in Figures 6(a) and 6(c), and the pipe diameter is different in Figures 6(a) and 6(d).

In the four cases, the variation trends of the particle velocity present an acceleration first followed by a deceleration and then an acceleration again with the simulation time. In the position of the particle factory, the particle trajectory is toward the negative direction of the $y$-axis due to gravity, and the particles are in the accelerated state during the falling process. The particle velocity suddenly decreases upon the first collision of the particles with the pipe wall, and the particles are bounced off the wall and reaccelerated by the flow field. Repeatedly, the particle velocity presents an acceleration first followed by a deceleration and then an acceleration again and finally becomes stabilized. The particle velocity shows an obvious stratification in the $y$-axis direction. The upper layer particle velocity is larger, and the lower layer particle velocity is smaller. This is due to the small number of particles in the upper layer and fewer particle collisions, so the particles accelerate significantly. However, the number of 


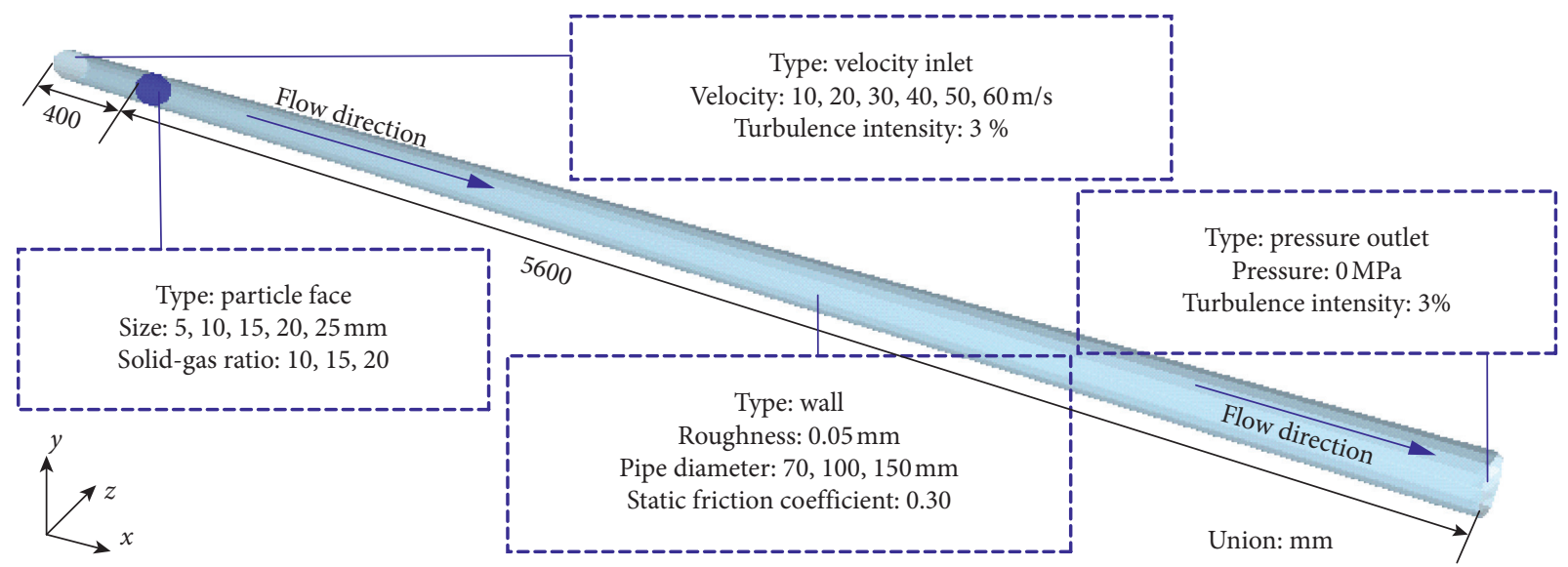

Figure 4: Simulation model.

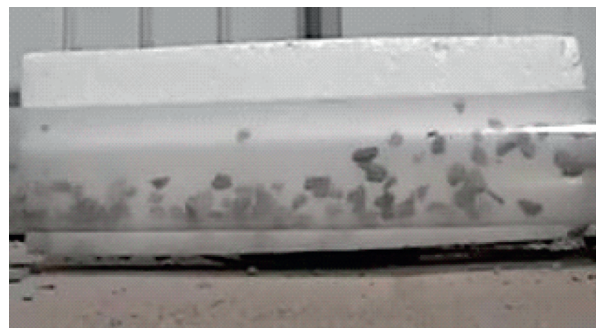

(a)

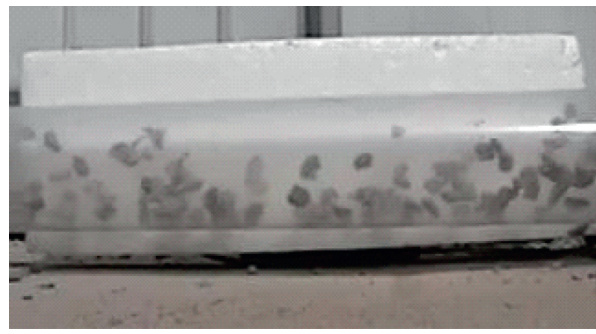

(c)

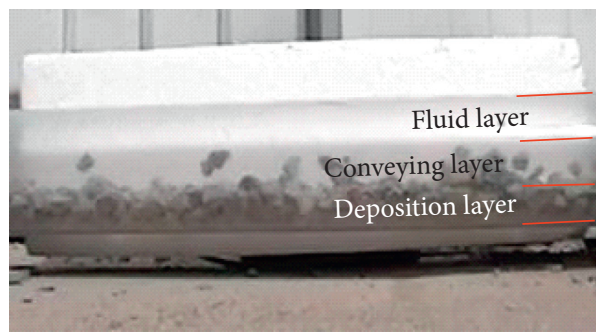

(e)

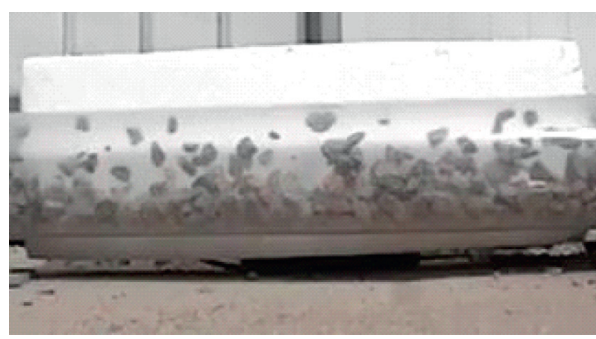

(g)

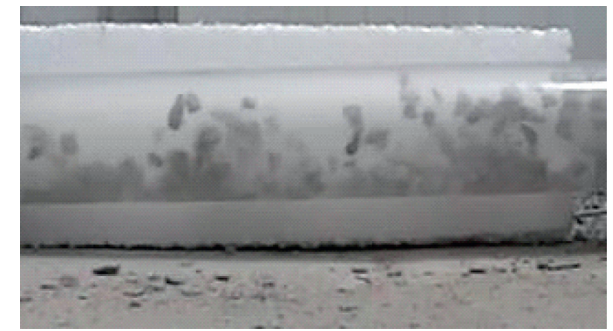

(b)

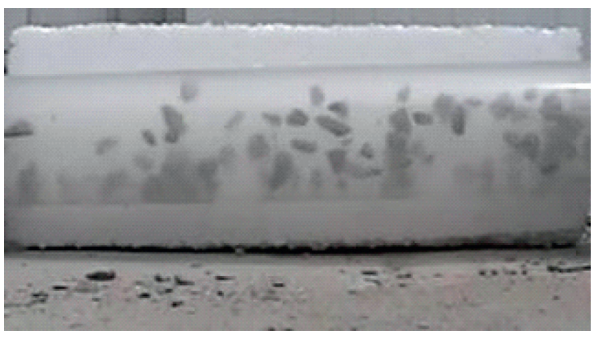

(d)

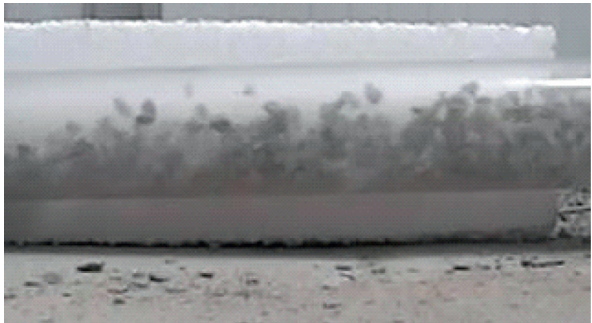

(f)

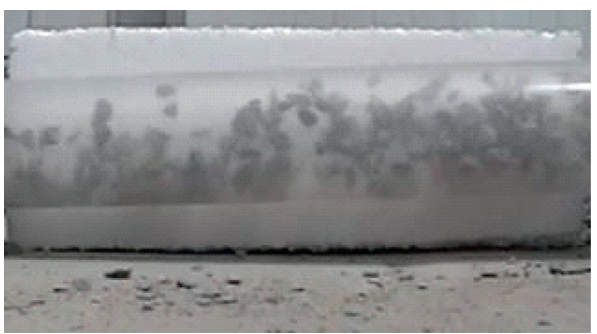

(h)

Figure 5: Instantaneous images of experiment videos. (a) No.1, flow field velocity $v=21 \mathrm{~m} / \mathrm{s}$, feeding rate $f_{\mathrm{p}}=1.12 \mathrm{~kg} / \mathrm{s}$. (b) No.2, flow field velocity $v=29 \mathrm{~m} / \mathrm{s}$, feeding rate $f_{\mathrm{p}}=1.12 \mathrm{~kg} / \mathrm{s}$. (c) No.3, flow field velocity $v=37 \mathrm{~m} / \mathrm{s}$, feeding rate $f_{\mathrm{p}}=1.12 \mathrm{~kg} / \mathrm{s}$. (d) No.4, flow field velocity $v=44 \mathrm{~m} / \mathrm{s}$, feeding rate $f_{\mathrm{p}}=1.12 \mathrm{~kg} / \mathrm{s}$. (e) No.1, flow field velocity $v=21 \mathrm{~m} / \mathrm{s}$, feeding rate $f_{\mathrm{p}}=2.25 \mathrm{~kg} / \mathrm{s}$. (f) No.1, flow field velocity $v=29 \mathrm{~m} / \mathrm{s}$, feeding rate $f_{\mathrm{p}}=2.25 \mathrm{~kg} / \mathrm{s}$. (g) No.1, flow field velocity $v=37 \mathrm{~m} / \mathrm{s}$, feeding rate $f_{\mathrm{p}}=2.25 \mathrm{~kg} / \mathrm{s}$. (h) No.1, flow field velocity $v=44 \mathrm{~m} / \mathrm{s}$, feeding rate $f_{\mathrm{p}}=2.25 \mathrm{~kg} / \mathrm{s}$. 
TABLE 5: Comparison of particle trajectories between experiment and simulation.

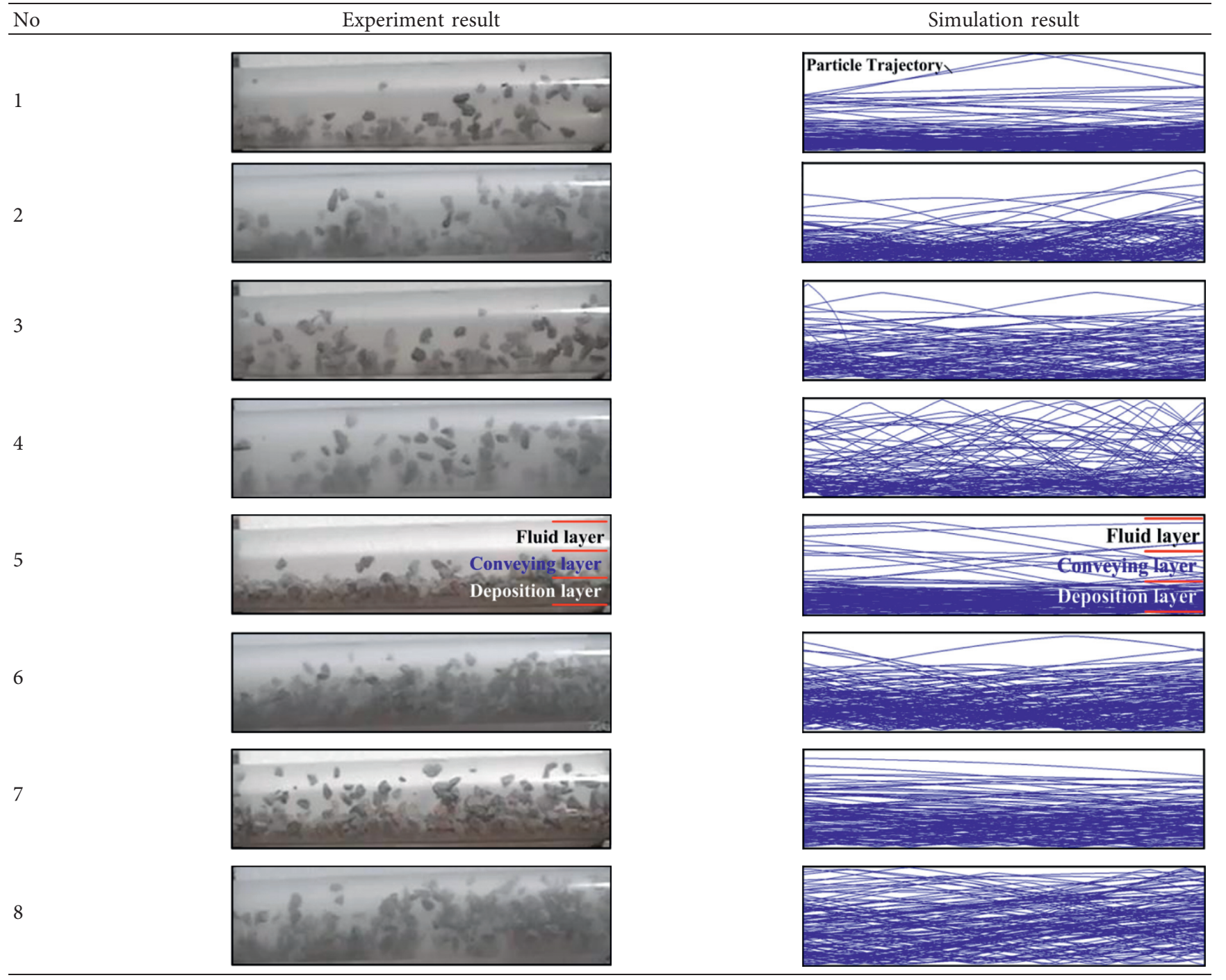

particles in the lower layer is large, and there are many particle collisions, and the particles are difficult to accelerate, resulting in an obvious stratification of the particle velocity in the $y$-axis direction.

Comparing Figures 6(a) and 6(b), under the same other conditions, the particle trajectories are messy and dispersed due to the increase in collision probability when the particle size increases. Comparing Figures 6(a) and 6(c), when the flow field velocity increases, the positions of the first particle collisions with the pipe wall are lagging behind. The pure flow field region appears in the upper layer, and the particle trajectories are mainly concentrated in the lower layer. Comparing Figures 6(a) and 6(d), when the pipe diameter increases, the positions of the first particle collisions with the pipe wall are also lagging behind and the pure flow field region above increases.

5.3.2. Pipe Abrasion. The maximum abrasion rate in the pipe is related to the working time. The service life of the pipe decreases with the increase in the maximum abrasion rate. The abrasion simulations are carried out using the abrasion model of equation (20) and considering the effects of the flow field velocity, particle size, solid-gas rate, and pipe diameter. Comparing the particle trajectories in Figure 6, the corresponding pipe abrasion is shown in Figure 7.

The main abrasion positions are concentrated in the first particle collision area and the pipe downstream. This is because the particles just enter the flow field and accelerate in the flow field during the falling process under the action of gravity. So the particle velocity is large when the particles first impact the pipe wall, which results in the large abrasion of the pipe wall. This is in line with the actual abrasion situation: the actual maximum abrasion areas in the pneumatic conveying system are often in the feeder mixing section where the particles first mix with the flow field. In the pipe downstream, some particles are impacted with the pipe wall again after they rebound in the first collision, which may lead to the high abrasion of the pipe wall.

The maximum abrasion areas of Figures 7 (a) and 7(b) appear downstream in the pipe. The maximum abrasion rate 


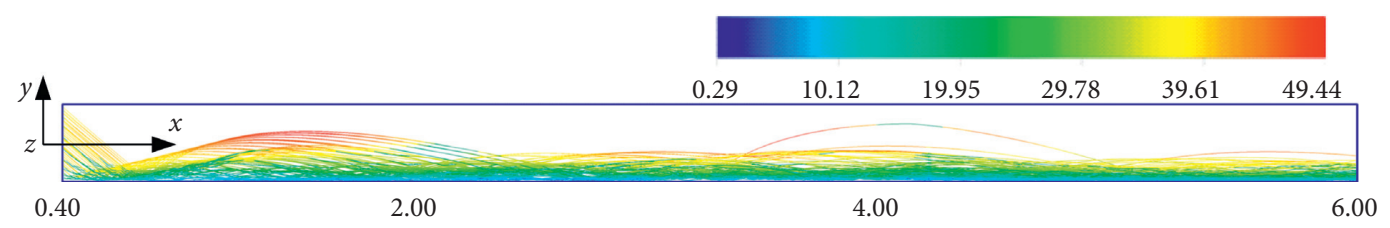

(a)

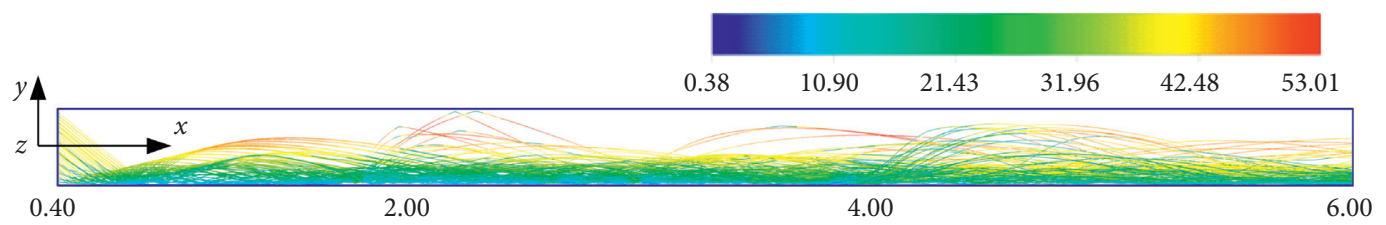

(b)

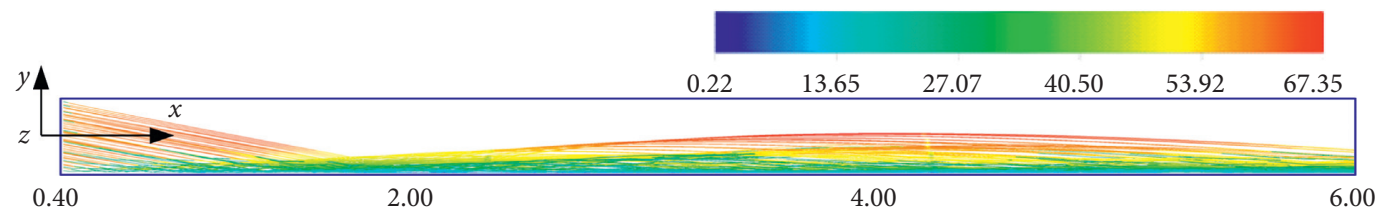

(c)

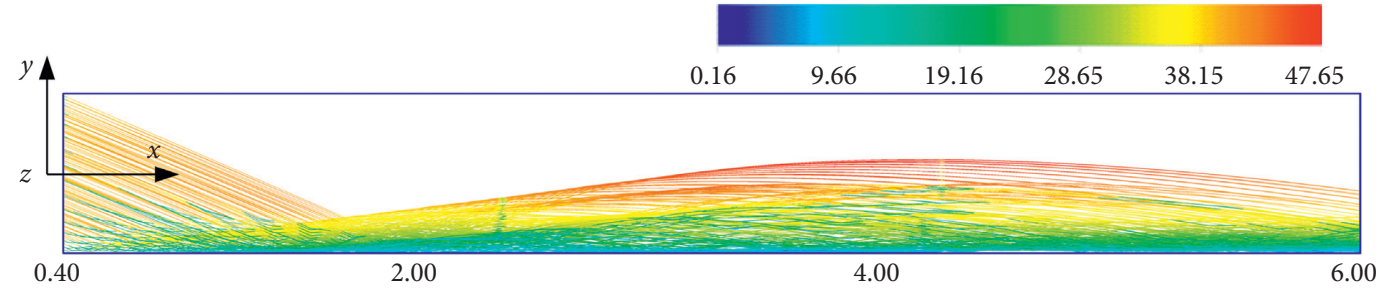

(d)

Figure 6: Particle trajectory in horizontal pipe. (a) $v_{\mathrm{g}}=40 \mathrm{~m} / \mathrm{s}, d_{\mathrm{p}}=5 \mathrm{~mm}, \mathrm{R}_{\mathrm{s}-\mathrm{g}}=10$, and $D=70 \mathrm{~mm}$. (b) $v_{\mathrm{g}}=40 \mathrm{~m} / \mathrm{s}, d_{\mathrm{p}}=15 \mathrm{~mm}, \mathrm{R}_{\mathrm{s}-\mathrm{g}}=10$, and $D=70 \mathrm{~mm}$. (c) $v_{\mathrm{g}}=60 \mathrm{~m} / \mathrm{s}, d_{\mathrm{p}}=5 \mathrm{~mm}, \mathrm{R}_{\mathrm{s}-\mathrm{g}}=10$, and $D=70 \mathrm{~mm}$. (d) $v_{\mathrm{g}}=40 \mathrm{~m} / \mathrm{s}, d_{\mathrm{p}}=5 \mathrm{~mm}, \mathrm{R}_{\mathrm{s}-\mathrm{g}}=10$, and $D=150 \mathrm{~mm}$.

decreases with the particle size, and the maximum abrasion position also changes. This is mainly because the increase in particle size reduces the number of particles in the pipe, and the particle collision probability also decreases under the same solid-gas rate.

Comparing Figures $7(\mathrm{a})$ and $7(\mathrm{c})$, the maximum abrasion rate increases greatly with the flow velocity. The maximum abrasion areas in Figure 7(c) appear in the positions of the first particle collision and the pipe downstream. The abrasion rate of the middle part of the pipe is less than the other parts. The particles extract more energy from the flow field due to the increase in the flow velocity, which leads to a faster particle velocity and smoother particle trajectories.

Comparing Figures 7(a) and 7(d), the maximum abrasion rate increases with the pipe diameter, and the maximum abrasion areas and abrasion situation are the same as those in Figure 7(c). As the pipe diameter increases, there is more space for the particles to accelerate. The particle velocity is larger upon the first collision, which results in the increase in the abrasion rate. In the middle of the pipe, the particle trajectories are concentrated and smooth, and the particle collisions are also moderated. However, in the pipe downstream, the particles reaccelerate and the abrasion rate increases again.

The abrasion simulations are carried out by using the simulation parameters in Table 5 to obtain the maximum abrasion rate for different particle sizes and flow field velocities. The simulation results are shown in Figure 8.

The maximum abrasion rate increases with the flow field velocity and decreases with the particle size. The maximum value occurs for a particle size of $5 \mathrm{~mm}$ and flow field velocity of $60 \mathrm{~m} / \mathrm{s}$; the minimum value occurs for a particle size of $25 \mathrm{~mm}$ and flow velocity of $20 \mathrm{~m} / \mathrm{s}$. When the flow field velocity is constant and the particle size is small, the particle size change has a great influence on the abrasion rate. However, the particle size change has less influence on the abrasion rate when the particle size is larger.

When the particle size is small $\left(d_{p}=5 \mathrm{~mm}\right.$ and $\left.10 \mathrm{~mm}\right)$, the maximum abrasion rate increases greatly with the flow field velocity. This is because the smaller the particle size is, the greater the particle number at the same solid-gas rate. When the flow velocity increases, the growth rate of the particle velocity is faster and the collision rate between the particles and the pipe wall is greater, which results in a large change in the maximum abrasion rate with the increase in the flow field velocity.

When the particle size is large $\left(d_{p}=15 \mathrm{~mm}, 20 \mathrm{~mm}\right.$, and $25 \mathrm{~mm}$ ), the maximum abrasion rate increases slightly with the flow field velocity, and the change trend is relatively stable. At this time, the larger the particle size is, the smaller the particle number is. The collision between the particles 


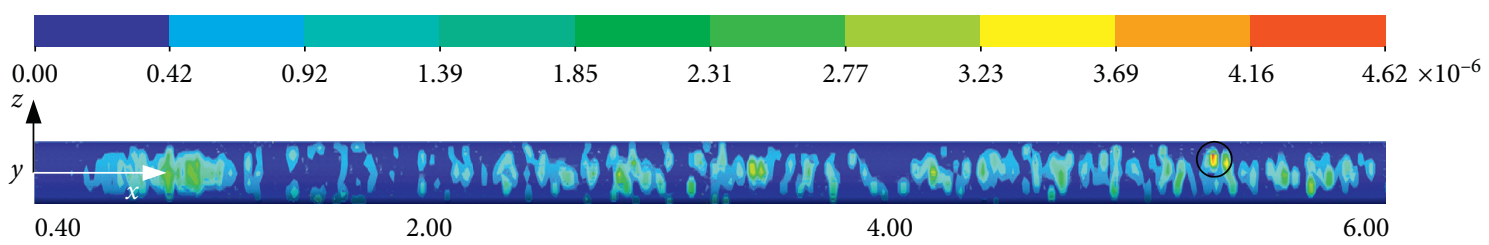

(a)

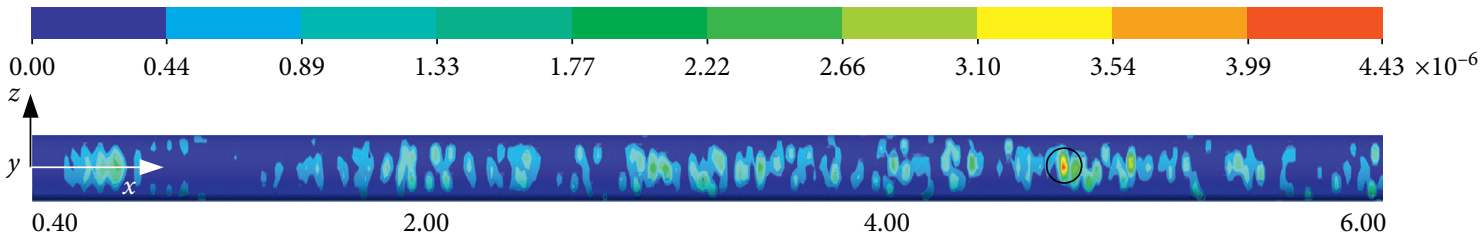

(b)

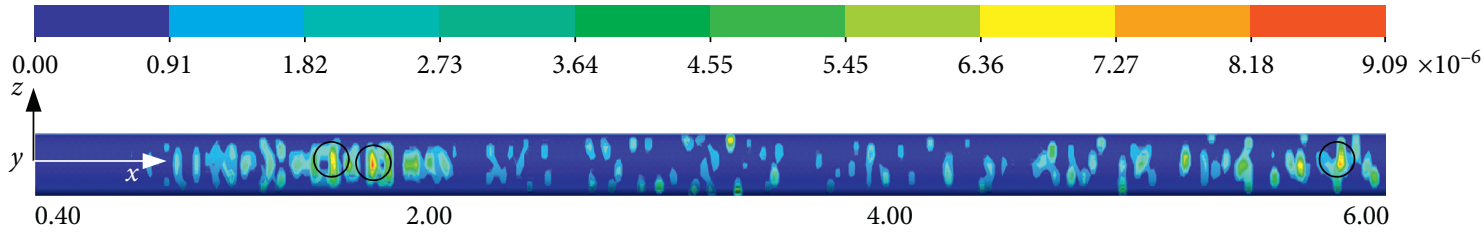

(c)

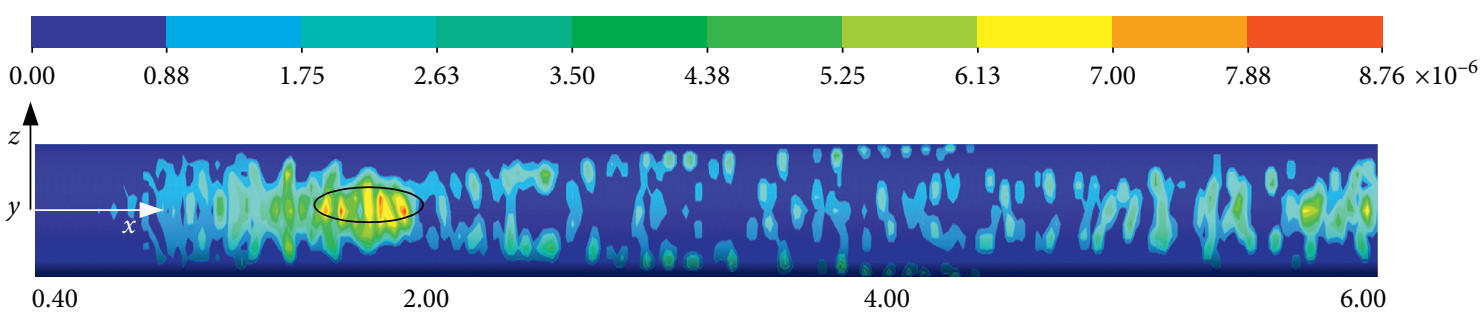

(d)

FiguRe 7: Contours of horizontal straight pipe abrasion rate under different conditions. (a) $v_{\mathrm{g}}=40 \mathrm{~m} / \mathrm{s}, d_{\mathrm{p}}=5 \mathrm{~mm}$, $\mathrm{R}_{\mathrm{s}-\mathrm{g}}=10$, and $D=70 \mathrm{~mm}$. (b) $v_{\mathrm{g}}=40 \mathrm{~m} / \mathrm{s}, d_{\mathrm{p}}=15 \mathrm{~mm}, \mathrm{R}_{\mathrm{s}-\mathrm{g}}=10$, and $D=70 \mathrm{~mm}$. (c) $v_{\mathrm{g}}=60 \mathrm{~m} / \mathrm{s}, d_{\mathrm{p}}=5 \mathrm{~mm}, \mathrm{R}_{\mathrm{s}-\mathrm{g}}=10$, and $D=70 \mathrm{~mm} .(\mathrm{d}) v_{\mathrm{g}}=40 \mathrm{~m} / \mathrm{s}, d_{\mathrm{p}}=5 \mathrm{~mm}, \mathrm{R}_{\mathrm{s}-}$ $\mathrm{g}=10$, and $D=150 \mathrm{~mm}$.

and the pipe wall is more severe due to the increase in the flow field velocity, but the decrease in the particle number does not make the maximum abrasion rate increase significantly. The effect of particle size and flow field velocity on the maximum abrasion rate indicates that the increase in flow field velocity directly increases the maximum abrasion rate, while the particle size and the particle number have a great influence on the maximum abrasion rate under the same solid-gas rate.

The abrasion simulations are carried out using the simulation parameters in Table 5 to obtain the relations between the maximum abrasion rate, solid-gas rate, and pipe diameter, which are shown in Figure 9.

The maximum abrasion rate increases with the solid-gas rate and the pipe diameter. The maximum value occurs for a solid-gas rate of 20 and pipe diameter of $150 \mathrm{~mm}$; the minimum value occurs for a solid-gas rate of 10 and pipe diameter of $70 \mathrm{~mm}$.

Under the same pipe diameter, the maximum abrasion rate increases with the solid-gas rate. Since the flow velocity is constant, the increase in the solid-gas rate can increase the particle number, resulting in an increase in the collision rate and the abrasion rate.
Under the same solid-gas rate, the maximum abrasion rate increases linearly with the pipe diameter. Since the flow field velocity and the solid-gas rate are fixed, the mass flow rate of the particles and the particle number increase with the pipe diameter, resulting in an increase in the collision probability and the abrasion rate. However, a large pipe diameter leads to enough of an acceleration space for the particles, which also leads to an increase in the collision probability and abrasion rate.

\section{Discussion}

6.1. Accuracy of the Simulation Results. Comparing the simulation and experiment results of the pressure drop, the pressure drop obtained by simulation and experiment varies greatly with the flow field velocity. This is because the DPM used in this paper does not consider the particle shape characteristics. The particle shape characteristics play a key role in the particle-particle and particle-wall collisions. When the flow velocity is low, the stratification of the flow field leads to more frequent particle-particle and particle-wall interactions, and even some of the particles accumulate at the pipe bottom. Therefore, the accuracy of the DPM simulation results may be 


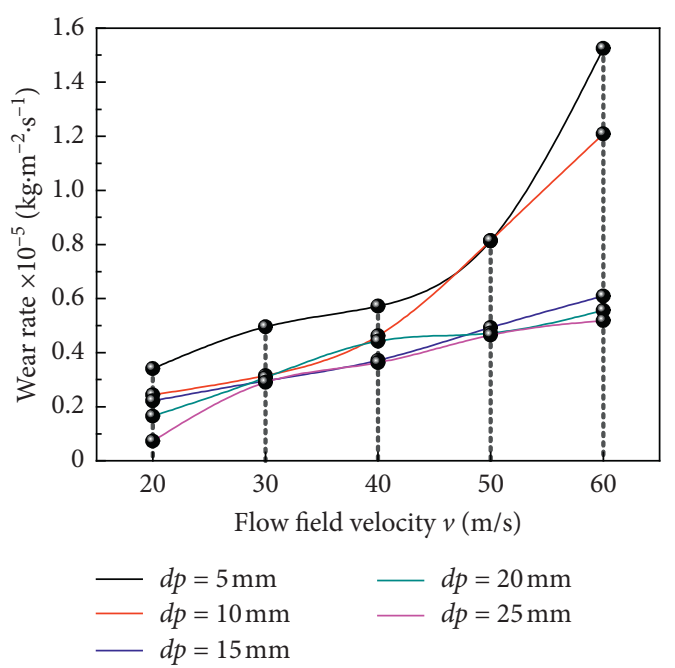

(a)

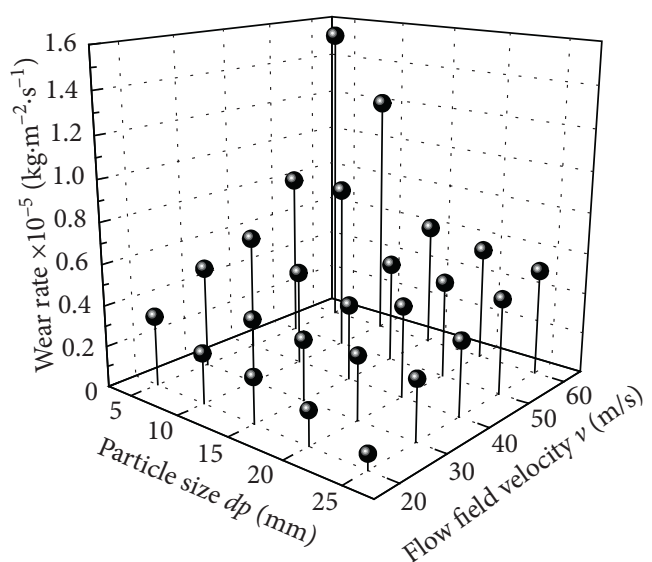

(b)

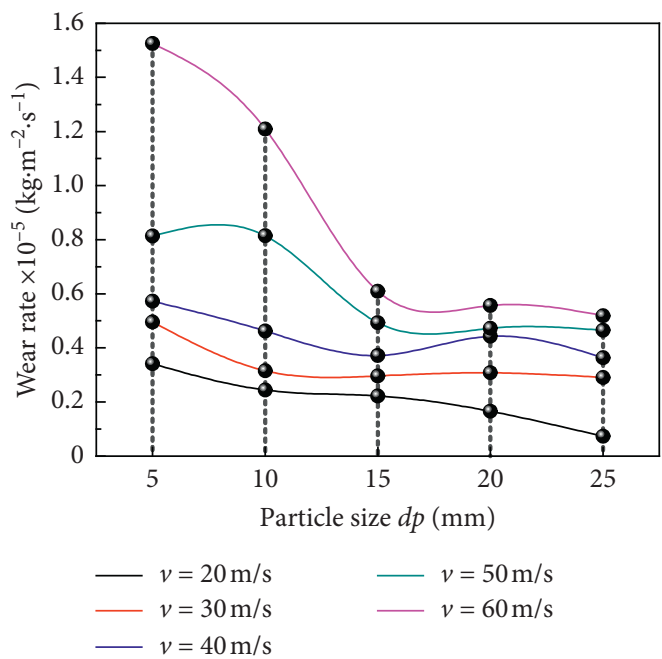

(c)

Figure 8: Relations between maximum abrasion rate and flow field velocity and particle size.

lower for low flow field velocity. However, when the flow velocity increases, the particles obtain more energy from the flow field, and some particles are even suspended in the flow field, which leads to a decrease in the collision probability. Therefore, the DPM simulation results are close to the experimental results for high flow field velocity.

6.2. Discussion of Pipe Abrasion. The abrasion experiments take a long time, and it is difficult to observe obvious experiment results. The analysis of pipe abrasion is based on the simulation results carried out in this paper. However, compared with the actual pneumatic conveying industrial system, the simulation results agree with the actual industrial situation in that the first collision position is the maximum abrasion position. Therefore, the DPM abrasion simulation results can be used as a reference for the design of pneumatic conveying systems.

During the pneumatic conveying process of coal particles, the particles will collide with the pipe wall under the action of gravity, which will cause the pipe wall to abrade. Under the same conditions, the flow field velocity, the pipe diameter, and solid-gas rate will increase the maximum abrasion rate. In the case of the pneumatic conveying industry, the abrasion of the pipe wall is an inevitable result of the interaction amount of the system operating conditions and particle collisions. For current pneumatic conveying systems, the service life is often extended by increasing the pipe thickness. However, based on the simulation results of this paper, reasonable configuration of the flow field velocity, particle diameter, pipe diameter, and solid-gas rate parameters help to extend the pipe life and increase the reliability of the pneumatic conveying piping system, but plenty of experiments are needed to confirm these results.

6.3. Limitation. The DPM simulation method used in this paper is only based on ANSYS Fluent software [42, 43]. Compared with the coupling simulation of EDEM software 


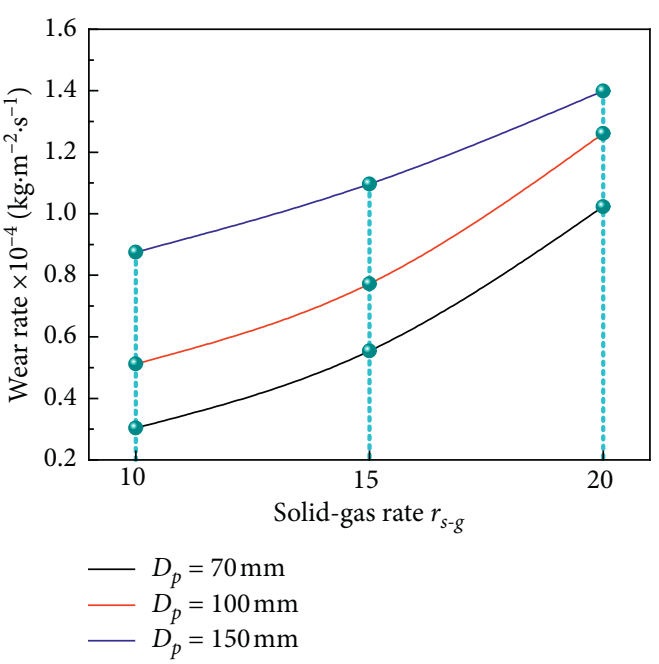

(a)

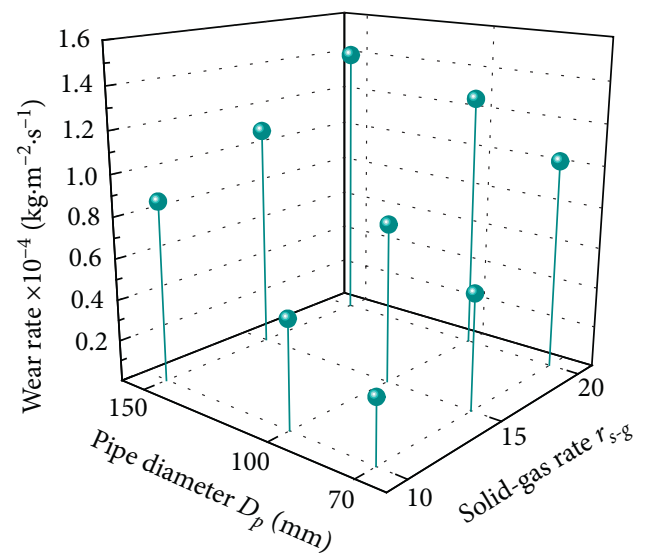

(b)

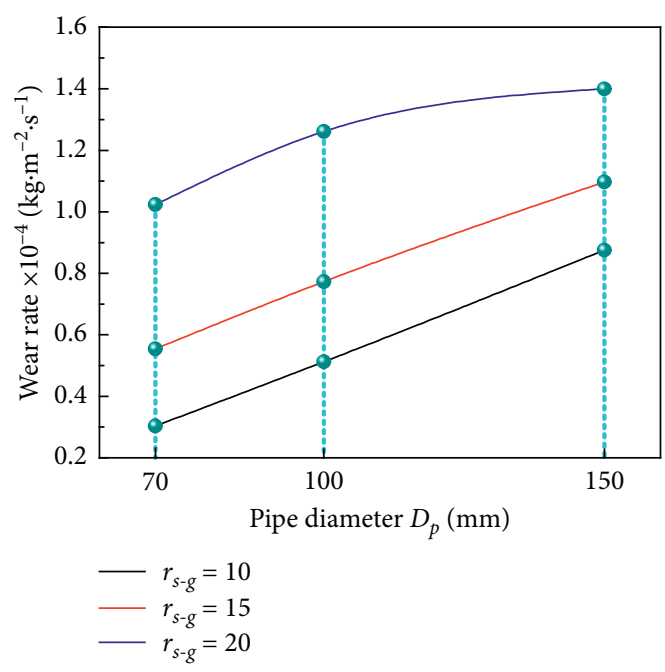

(c)

FIGURE 9: Relations between maximum abrasion rate, solid-gas rate, and pipe diameter.

and ANSYS Fluent software [44, 45], it can predict the particle motion and has the advantage of a short calculation time, but the reliability needs to be improved due to ignoring the particle shape.

The shape of particles, such as coal and rock, has diverse characteristics [46], and the shape of particles has a large influence on particle collision and motion in the flow field. In the simulation of this paper, the particle shape characteristic is ignored due to simplification of the equation of particle motion in the flow field. The fluid drag and Saffman lift used in this paper are both based on the present theories, which came from small particles (size less than $5 \mathrm{~mm}$ ). Therefore, there is a certain gap between the simulation results and the actual experiment. In order to improve the accuracy of the simulation, the next step will consider the influence of particle shape and particle size on the particle motion equation and particle collision behavior.

\section{Conclusions}

(1) The horizontal pneumatic conveying experiments are carried out with large coal particles. The results show that the flow field exhibits a stratification phenomenon and is divided into three layers when the flow velocity is small. The upper layer is the fluid layer and is mainly high-velocity fluid, the middle is the conveying layer and is a mixture of particles and fluid, and the bottom is the deposition layer and is mainly coal particles with low velocity or that are static. When the flow field velocity increases, the stratification phenomenon disappears.

(2) Comparative simulations are carried out using simulation conditions similar to the experiment, and the results show that the DPM model is feasible for predicting the horizontal pneumatic conveying of large coal particles from the particle trajectories. 
(3) Under the condition of constant solid-gas rate and pipe diameter, the influences of the particle size and flow field velocity on the pipe abrasion are obtained. The maximum abrasion rate increases with the flow field velocity and decreases with the particle size. In the case of constant particle size and flow field velocity, the influences of the solid-gas rate and pipe diameter on the pipe abrasion are obtained. The maximum abrasion rate increases with the pipe diameter and the solid-gas rate.

(4) Comparing the simulation and experiment results, the accuracy and limitations of the DPM simulation method used in this paper are discussed. The DPM simulation method has the advantage of a short calculation time; however, there is a certain gap between the simulation results and the actual experiment because the particle shape is not considered and the particle forces are both based on the present theories, which came from small particles. Therefore, the next step will be to consider the influence of the particle shape and particle size on the particle motion equation and particle collision behavior to improve the simulation accuracy and reliability.

\section{Nomenclature}

$a$ : The computing coefficient of drag force

$b$ : The computing coefficient of Saffman lift force

$C\left(d_{p}\right)$ : The function of particle diameter, $C\left(d_{p}\right)=1.8 \times 10^{-9}$

$d_{l k}: \quad$ The deformation tenser

$e_{n}$ : The normal recovery factor

$f: \quad$ The coefficient generated from the solution of elliptic integral

$\mathbf{F}_{d}: \quad$ The drag force vector of particle

$\mathbf{F}_{n}: \quad$ The normal contact forces

$\mathbf{F}_{o}$ : The other forces vector of particle

$k_{n}$ : The normal contact coefficient

$K: \quad$ The constant of Saffman lift force, $K=2.594$

$m_{p}: \quad$ The particle mass

$n_{k}$ : The number density of particle phase

$v_{j}$ : The velocity component of gas phase on the $j$ direction

$v_{r}: \quad$ The relative particle velocity

$x_{j}$ : $\quad$ The $j$ direction of coordinate

a: $\quad$ The normal contact displacement vector

$\theta: \quad$ The impact angle

$v_{p k i}$ : The velocity component of solid phase on the $i$ direction

$\rho: \quad$ The density of gas phase

$\tau_{r k}: \quad$ The particle relaxation time

$A_{w}: \quad$ The area of the cell face at the wall

$b(v)$ : The function of relative particle velocity, $b(v)=2.6$

$d_{k l}: \quad$ The deformation tenser

$d_{p}: \quad$ The particle diameter

$e_{r}: \quad$ The tangential recovery factor

$f(\alpha)$ : The function of impact angle

$\mathbf{F}_{g}$ : The gravitational force vector of particle

$\mathbf{F}_{t}$ : The tangential contact forces

$\mathbf{F}_{S}$ : The Saffman lift force vector of particle $k_{t}: \quad$ The tangential contact coefficient

$m_{k}$ : The quality of single particle

$n$ : The coefficient generated from the solution of elliptic integral

S: $\quad$ The volume fraction of solid phase in gas-solid mixture

$\mathbf{v}_{p}:$ The particle velocity vector

$v_{r i}: \quad$ The difference value between the gas and solid

$\alpha$ : The impact angle of the particle path with the wall face

$\boldsymbol{\delta}: \quad$ The tangential contact displacement vector

$\mu$ : The gas dynamic viscosity

$\xi: \quad$ The volume fraction term

$\rho_{p}: \quad$ The density of solid phase.

\section{Data Availability}

The data used to support the findings of this study are available from the corresponding author upon request.

\section{Disclosure}

Daolong Yang and Ge Li are co-first authors of the article.

\section{Conflicts of Interest}

The authors declare that they have no conflicts of interest.

\section{Acknowledgments}

The work was funded by the National Natural Science Foundation of China (51705222 and 51675521), the National Natural Science Foundation of Jiangsu Province (BK20170241), and the State Key Laboratory of Process Automation in Mining and Metallurgy, and the Beijing Key Laboratory of Process Automation in Mining and Metallurgy (BGRIMM-KZSKL-2019-07).

\section{References}

[1] N. Huber and M. Sommerfeld, "Modelling and numerical calculation of dilute-phase pneumatic conveying in pipe systems," Powder Technology, vol. 99, no. 1, pp. 90-101, 1998.

[2] K. Li, S. B. Kuang, R. H. Pan, and A. B. Yu, "Numerical study of horizontal pneumatic conveying: effect of material properties," Powder Technology, vol. 251, pp. 15-24, 2014.

[3] R. Dhurandhar, J. P. Sarkar, and B. Das, "The recent progress in momentum, heat and mass transfer studies on pneumatic conveying: a review," Heat and Mass Transfer, vol. 54, no. 9, pp. 2617-2634, 2018.

[4] K. Takabatake, Y. Mori, J. G. Khinast, and M. Sakai, "Numerical investigation of a coarse-grain discrete element method in solid mixing in a spouted bed," Chemical Engineering Journal, vol. 346, pp. 416-426, 2018.

[5] B. J. Azzopardi, K. Jackson, J. P. Robinson, R. Kaji, M. Byars, and A. Hunt, "Fluctuations in dense phase pneumatic conveying of pulverised coal measured using electrical capacitance tomography," Chemical Engineering Science, vol. 63, no. 9, pp. 2548-2558, 2008. 
[6] J.-W. Zhou, L.-G. Xu, and C.-L. Du, "Prediction of lump coal particle pickup velocity in pneumatic conveying," Powder Technology, vol. 343, pp. 599-606, 2019.

[7] C. Xu, C. Liang, B. Zhou, and S. Wang, "HHT analysis of electrostatic fluctuation signals in dense-phase pneumatic conveying of pulverized coal at high pressure," Chemical Engineering Science, vol. 65, no. 4, pp. 1334-1344, 2010.

[8] D. Yang, J. Li, B. Xing, and Y. Wang, "Recent patents on gangue pneumatic filling for coal auger mining method," Recent Patents on Mechanical Engineering, vol. 11, no. 1, pp. 31-40, 2018.

[9] D. Yang, B. Xing, J. Li, and Y. Wang, "Recent patents on pressurization and dedusting for pneumatic conveying," Recent Patents on Mechanical Engineering, vol. 11, no. 3, pp. 180-189, 2018.

[10] J. J. Fitzpatrick, "Particle properties and the design of solid food particle processing operations," Food and Bioproducts Processing, vol. 85, no. 4, pp. 308-314, 2007.

[11] A. Sokolichin, G. Eigenberger, A. Lapin, and A. Lübert, "Dynamic numerical simulation of gas-liquid two-phase flows Euler/Euler versus Euler/Lagrange," Chemical Engineering Science, vol. 52, no. 4, pp. 611-626, 1997.

[12] M. Sanjosé, J. M. Senoner, F. Jaegle, B. Cuenot, S. Moreau, and T. Poinsot, "Fuel injection model for Euler-Euler and EulerLagrange large-eddy simulations of an evaporating spray inside an aeronautical combustor," International Journal of Multiphase Flow, vol. 37, no. 5, pp. 514-529, 2011.

[13] W. P. Adamczyk, A. Klimanek, R. A. Białecki, G. Węcel, P. Kozołub, and T. Czakiert, "Comparison of the standard Euler-Euler and hybrid Euler-Lagrange approaches for modeling particle transport in a pilot-scale circulating fluidized bed," Particuology, vol. 15, pp. 129-137, 2014.

[14] P. Mellin, Q. Zhang, E. Kantarelis, and W. Yang, "An EulerEuler approach to modeling biomass fast pyrolysis in fluidized-bed reactors - focusing on the gas phase," Applied Thermal Engineering, vol. 58, no. 1-2, pp. 344-353, 2013.

[15] W. Lou and M. Zhu, "Numerical simulation of gas and liquid two-phase flow in gas-stirred systems based on euler-euler approach," Metallurgical and Materials Transactions B, vol. 44, no. 5, pp. 1251-1263, 2013.

[16] S. Laín and M. Sommerfeld, "Characterisation of pneumatic conveying systems using the Euler/Lagrange approach," Powder Technology, vol. 235, pp. 764-782, 2013.

[17] P. Pepiot and O. Desjardins, "Numerical analysis of the dynamics of two- and three-dimensional fluidized bed reactors using an Euler-Lagrange approach," Powder Technology, vol. 220, pp. 104-121, 2012.

[18] Y. Li, J. Zhang, and L.-S. Fan, "Numerical simulation of gasliquid-solid fluidization systems using a combined CFDVOF-DPM method: bubble wake behavior," Chemical Engineering Science, vol. 54, no. 21, pp. 5101-5107, 1999.

[19] B. H. Xu and A. B. Yu, "Numerical simulation of the gas-solid flow in a fluidized bed by combining discrete particle method with computational fluid dynamics," Chemical Engineering Science, vol. 52, no. 16, pp. 2785-2809, 1997.

[20] L. Sanchez, N. Vasquez, G. E. Klinzing, and S. Dhodapkar, "Characterization of bulk solids to assess dense phase pneumatic conveying," Powder Technology, vol. 138, no. 2-3, pp. 93-117, 2003.

[21] F. Zhou, S. Hu, Y. Liu, C. Liu, and T. Xia, "CFD-DEM simulation of the pneumatic conveying of fine particles through a horizontal slit," Particuology, vol. 16, pp. 196-205, 2014.
[22] S. Watano, S. Saito, and T. Suzuki, "Numerical simulation of electrostatic charge in powder pneumatic conveying process," Powder Technology, vol. 135-136, pp. 112-117, 2003.

[23] S. Watano, "Mechanism and control of electrification in pneumatic conveying of powders," Chemical Engineering Science, vol. 61, no. 7, pp. 2271-2278, 2006.

[24] K. Choi, Y. Endo, and T. Suzuki, "Experimental study on electrostatic charges and discharges inside storage silo during loading of polypropylene powders," Powder Technology, vol. 331, pp. 68-73, 2018.

[25] M. Güner, "Pneumatic conveying characteristics of some agricultural seeds," Journal of Food Engineering, vol. 80, no. 3, pp. 904-913, 2007.

[26] H. Ghafori and M. Sharifi, "Numerical and experimental study of an innovative design of elbow in the pipe line of a pneumatic conveying system," Powder Technology, vol. 331, pp. 171-178, 2018.

[27] D. Yang, J. Li, K. Zheng, C. Du, and S. Liu, "Impact-crush separation characteristics of coal and gangue," International Journal of Coal Preparation and Utilization, vol. 38, no. 3, pp. 127-134, 2018.

[28] J.-W. Zhou, Y. Liu, C.-1. Du, and S.-y. Liu, "Effect of the particle shape and swirling intensity on the breakage of lump coal particle in pneumatic conveying," Powder Technology, vol. 317, pp. 438-448, 2017.

[29] J.-w. Zhou, C.-1. Du, and Z.-1. Ma, "Influence of swirling intensity on lump coal particle pickup velocity in pneumatic conveying," Powder Technology, vol. 339, pp. 470-478, 2018.

[30] J. Zhou, Y. Liu, C. Du, S. Liu, and J. Li, "Numerical study of coarse coal particle breakage in pneumatic conveying," Particuology, vol. 38, pp. 204-214, 2018.

[31] D. Yang, B. Xing, J. Li, Y. Wang, N. Hu, and S. Jiang, "Experiment and simulation analysis of the suspension behavior of large $(5-30 \mathrm{~mm})$ nonspherical particles in vertical pneumatic conveying," Powder Technology, vol. 354, pp. 442-455, 2019.

[32] D. L. Yang, B. S. Xing, J. P. Li et al., "Experimental study on the injection performance of the gas-solid injector for large coal particles," Powder Technology, vol. 354, pp. 442-455, 2019.

[33] J. Li, F. Zhou, D. Yang, B. Yu, and Y. Li, "Effect of swirling flow on large coal particle pneumatic conveying," Powder Technology, vol. 362, pp. 745-758, 2020.

[34] T.-H. Shih, W. W. Liou, A. Shabbir, Z. Yang, and J. Zhu, “A new k- $\epsilon$ eddy viscosity model for high Reynolds number turbulent flows," Computers \& Fluids, vol. 24, no. 3, pp. 227-238, 1995.

[35] A. Li and G. Ahmadi, "Dispersion and deposition of spherical particles from point sources in a turbulent channel flow," Aerosol Science and Technology, vol. 16, no. 4, pp. 209-226, 1992.

[36] P. G. Saffman, "The lift on a small sphere in a slow shear flow," Journal of Fluid Mechanics, vol. 22, no. 2, pp. 385-400, 1965.

[37] A. M. Reynolds, "On the formulation of Lagrangian stochastic models for heavy-particle trajectories," Journal of Colloid and Interface Science, vol. 232, no. 2, pp. 260-268, 2000.

[38] D. L. Yang, J. P. Li, C. L. Du, H. X. Jiang, and K. H. Zheng, "Injection performance of a gas-solid injector based on the particle trajectory model," Advances in Materials Science and Engineering, vol. 23, 2015.

[39] C. D. Dritselis and N. S. Vlachos, "Large eddy simulation of gas-particle turbulent channel flow with momentum exchange between the phases," International Journal of Multiphase Flow, vol. 37, no. 7, pp. 706-721, 2011. 
[40] J. K. Edwards, B. S. McLaury, and S. A. Shirazi, "Evaluation of alternative pipe bend fittings in erosive service," Proceedings of ASME Fluids Engineering Summer Meeting, vol. 22, 2000.

[41] D. Aitaliyahia, G. Baruzzi, W. G. Habashi et al., "Anisotropic mesh adaptation: towards user-independent, mesh-independent and solver-independent CFD. Part II. Structured grids," International Journal for Numerical Methods in Fluids, vol. 39, no. 8, pp. 675-702, 2002.

[42] O. Rybdylova, M. A. Qubeissi, M. Braun et al., "A model for droplet heating and its implementation into ANSYS Fluent," International Communications in Heat and Mass Transfer, vol. 76, pp. 265-270, 2016.

[43] M. Thiruvengadam, Y. Zheng, and J. C. Tien, "DPM simulation in an underground entry: Comparison between particle and species models," International Journal of Mining Science and Technology, vol. 26, no. 3, pp. 487-494, 2016.

[44] M. Azimian, M. Lichti, and H.-J. Bart, "Investigation of particulate flow in a channel by application of CFD, DEM and LDA/PDA," The Open Chemical Engineering Journal, vol. 8, no. 1, pp. 1-11, 2014.

[45] A. T. Adema, Y. Yang, and R. Boom, "Discrete element method-computational fluid dynamic simulation of the materials flow in an iron-making blast furnace," ISIJ International, vol. 50, no. 7, pp. 954-961, 2010.

[46] K. Zheng, C. Du, J. Li, B. Qiu, L. Fu, and J. Dong, "Numerical simulation of the impact-breakage behavior of non-spherical agglomerates," Powder Technology, vol. 286, pp. 582-591, 2015. 